Bull. Mater. Sci., Vol. 3, Number 4, December, 1981, pp. 443-445. (C) Printed in India.

\title{
Determination of the composition of binary systems by the ratio method employing SEM-EDAX
}

\author{
G N SUBBANNA \\ Materials Research Laboratory, Indian Institute of Science, Bangalore 560 012, India \\ MS received 19 June 1981
}

Abstract. By employing x-ray emission in a scanning electron microscope (SEM), it has been shown that compositions of binary systems such as As-Se glasses, Al-Zn alloys and copper sulphides can be determined.

Keywords. X-ray emission; scanning electron microscopy; binary systems.

\section{Introduction}

Phase identification and determination of phase composition are major problems in solid state synthesis especially when the product is in the form of a polycrystalline powder or compact. It has been recently shown (Cheetham and Skarnulis) that analysis of characteristic $x$-ray emission from thin sections of the sample in a transmission electron microscope provides a reliable method for determining the composition of individual crystallites in a polycrystalline mixture. The method is based on the fact that the ratio of concentration $C_{x} / C_{y}$ of two elements $x$ and $y$ in a given crystal is proportional to the ratio of intensities $\left(I_{x} / I_{y}\right)$ of their characteristic X-ray emission lines.

$$
C_{x} / C_{y}=K_{x y}\left(I_{x} / I_{y}\right)
$$

where $K_{x y}$ is a constant for the particular pair of elements. $K_{x y}$ can be evaluated using either a known compound or from the ionization cross-section, fluorescence and specimen-detector geometry (Russ 1976).

This so called ratio method has been successfully applied to several classes of solids such as alloys, minerals, metal oxides and sulphides by carrying out $x$-ray microanalysis in a transmission electron microscope (Cliff and Lorimer 1975; Goldstein 1979 and Cheetham 1980). We have examined whether the ratio method is applicable for the determination of phase composition of solids by making use of $\mathrm{x}$-ray emission in a scanning electron microscope.

\section{Experimental}

We have selected three different binary systems for our study (i) As-Se glasses (ii) $\mathrm{Al}-\mathrm{Zn}$ alloys and (iii) $\mathrm{Cu}-\mathrm{S}$ sulphides. Samples of (i) and (ii) were in the form of sheets, 


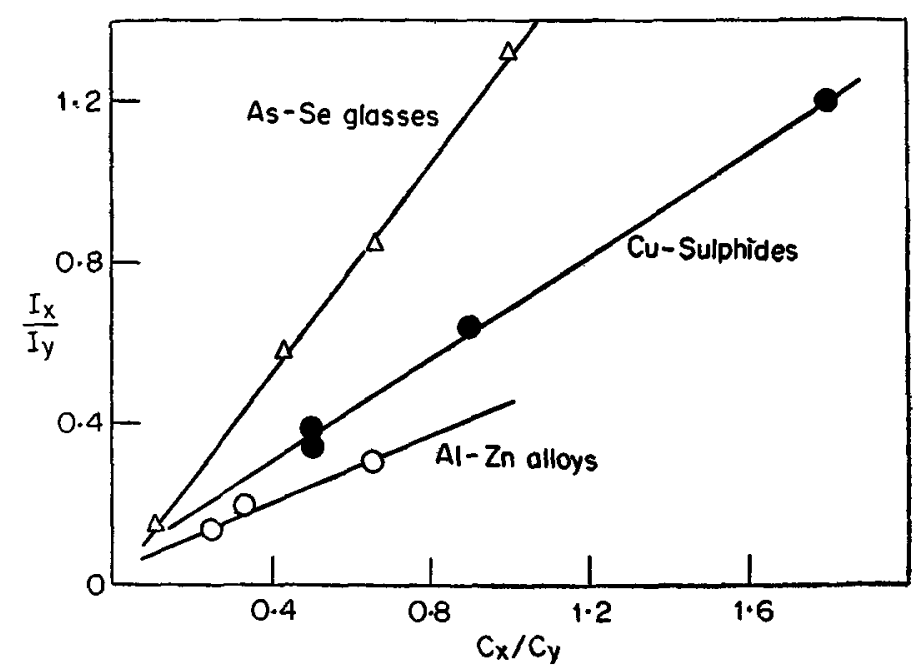

Figure 1. X-ray emission intensity ratio $v s$ molar concentration ratio.

while samples of (iii) were polycrystalline powders. Specimens pertaining to each system were mounted on a single holder. As-Se glasses were coated with carbon to make them conducting. X-ray microanalysis were carried out in a cambridge stereoscan S-150 microscope fitted with a Philips X-ray detector at $20 \mathrm{keV}$ electron energy. The sample holder was tilted by about $40^{\circ}$ w.r.t. electron beam and rotated about beam axis so that the holder was directly facing the $\mathrm{X}$-ray detector.

$X$-ray spectra were obtained for a preset time $(40-100 \mathrm{sec})$ with separate windows set for each $k$-peak and to the base line on the left side of each peak (to correct for the background intensity). For samples of (i) and (ii) both area and point analysis were carried out; for samples of (iii) only point analysis was made. In each case $x$-ray emission intensities were determined in at least three different regions of the sample to ensure compensational homogeneity.

\section{Results and Discussion}

The intensity ratios $k_{a}(\mathrm{As}) / k_{a}(\mathrm{Se})$ for (i), $k_{a}(\mathrm{Zn}) / k_{a}(\mathrm{Al})$ for (ii) and $k_{a}(\mathrm{Cu}) / k_{\alpha}$ (S) for (iii) are plotted in figure 1 against the molar concentration ratios which are already known (i and ii) or have been determined by other methods (iii). From figure 1 we see that the plots are linear in all the three cases over the composition range investigated. In the case of $\mathrm{Cu}-\mathrm{S}$ system two different samples having the same $\mathrm{Cu} / \mathrm{S}$ ratio viz $\mathrm{LaCuS}_{2}$ and $\mathrm{CaFeS}_{2}$ (chalcopyrite) were investigated. We see that the data points are close together in the figure indicating that the influence of the third constituent on the ratio is only minimal.

We have also examined ternary compounds such as $\mathrm{MgV}_{2} \mathrm{O}_{4}$ and $\mathrm{MgV}_{2} \mathrm{~S}_{4}$ in which the ratio of two elements is constant, but the third element is different. By this method, we have found that the $k_{a}(\mathrm{Mg}) / k_{a}(\mathrm{~V})$ ratio is the same in both the cases, 0.081 and 0.09 respectively indicating that the influence of the third constituent on the intensity ratios is marginal. 
The present study shows that just as with TEM x-ray emission in SEM can be made use of for characterization of complex materials.

\section{Acknowledgements}

The author is thankful to Professor C N R Rao for suggesting the problem and Drs K J Rao, J Gopalakrishnan and Mr T S Panchapagesan for providing the samples.

\section{References}

Cheetham A K 1980 Nature 288469

Cheetham A K and Skarnulis A J 1981 Anal. Chem. 531060

Cliff G and Lorimer G W 1975 J. Microsc. 103203

Goldstein J I $1979 \mathrm{~J}$. Metals 3166

Russ R C 1976 EDAX EDITor 642 